Southern Illinois University Carbondale

OpenSIUC

Publications

Department of Zoology

$12-2005$

\title{
Limited Dispersal and Heterogeneous Predation Risk Synergistically Enhance Persistence of Rare Prey
}

Brett J. Goodwin

Clive G. Jones

Eric M. Schauber

Southern Illinois University Carbondale

Richard S. Ostfeld

Follow this and additional works at: http://opensiuc.lib.siu.edu/zool_pubs

(C) 2005 by the Ecological Society of America

Published in Ecology, Vol. 86, No. 12 (December 2005) at doi: 10.1890/04-1057

\section{Recommended Citation}

Goodwin, Brett J., Jones, Clive G., Schauber, Eric M. and Ostfeld, Richard S. "Limited Dispersal and Heterogeneous Predation Risk Synergistically Enhance Persistence of Rare Prey." (Dec 2005).

This Article is brought to you for free and open access by the Department of Zoology at OpenSIUC. It has been accepted for inclusion in Publications by an authorized administrator of OpenSIUC. For more information, please contact opensiuc@lib.siu.edu. 


\title{
LIMITED DISPERSAL AND HETEROGENEOUS PREDATION RISK SYNERGISTICALLY ENHANCE PERSISTENCE OF RARE PREY
}

\author{
Brett J. Goodwin, ${ }^{1}$ Clive G. Jones, Eric M. Schauber, ${ }^{2}$ and Richard S. Ostfeld \\ Institute of Ecosystem Studies (IES), Millbrook, New York 12545-0129 USA
}

\begin{abstract}
White-footed mice prey on gypsy moth pupae while foraging for other, more abundant food. Mice appear capable of locally extirpating moths since mice exert high predation pressure on sparse pupae and are numerically decoupled from moth populations. Nevertheless, during 23 years of monitoring, moths persisted at scales $>1$ ha despite frequent extinctions at smaller spatial scales. We hypothesized that spatially heterogeneous intensity in mouse foraging and/or limited moth dispersal might allow moth persistence. Using a spatially explicit, individual-based, empirically parameterized model, we show that neither spatially heterogeneous predation by mice, nor limited moth dispersal alone allows moth persistence at typical mouse densities. However, synergy between both factors allows moth population persistence at naturally occurring mouse densities. For example, in models with $40 \mathrm{mice} / \mathrm{ha}$, both limited moth dispersal with spatially homogeneous predation risk and spatially heterogeneous predation risk with unlimited moth dispersal had a $0 \%$ chance of moth persistence, but the combination of limited dispersal and heterogeneous predation risk resulted in a $\sim 75 \%$ chance of moth persistence. Furthermore, both for limited moth dispersal with spatially homogeneous predation risk and for spatially heterogeneous predation risk with unlimited moth dispersal, moth persistence was only guaranteed at very low mouse densities, while the combination of limited moth dispersal with heterogeneous predation guaranteed moth persistence within a broad range of mouse densities. The findings illustrate a novel mechanism of "spatial selection and satiation" that can enhance rare species persistence under intense incidental predation by generalist predators.
\end{abstract}

Key words: $\quad$ gypsy moth; limited dispersal; Lymantria dispar; Peromyscus leucopus; population persistence; predation risk; spatial heterogeneity; white-footed mouse.

\section{INTRODUCTION}

Understanding how prey populations persist at high predation rates is central to population ecology, conservation biology, and pest management. Prey attacked by specialist predators are thought to avoid local extinction when predator abundance declines in response to declining prey populations. However, unlike specialists, generalist predators may remain abundant when a particular prey species becomes scarce. Thus, prey that are the targets of incidental predation (Schmidt et al. 2001) by abundant generalists may be locally extirpated (Murdoch and Bence 1987, Savidge 1987, Wilson et al. 1998).

White-footed mouse (Peromyscus leucopus) predation on gypsy moth pupae (Lymantria dispar) in North America is a clear case of incidental predation on an ofttimes scarce prey. Gypsy moths, introduced into Massachusetts from Europe around 1869, have spread

Manuscript received 30 June 2004; revised 27 January 2005; accepted 31 January 2005. Corresponding Editor: M. D. Eubanks. For reprints of this Special Feature, see footnote 1, p. 3137.

${ }^{1}$ Present address: Department of Biology, Box 9019, University of North Dakota, Grand Forks, North Dakota 58202 9019 USA. E-mail: brett.goodwin@und.nodak.edu

${ }^{2}$ Present address: Cooperative Wildlife Research Laboratory and Department of Zoology, Southern Illinois University, Carbondale, Illinois 62901-6504 USA. north into Canada, west to the Great Lakes, and south to Virginia (Liebhold et al. 1992). Moths periodically outbreak, causing widespread defoliation, but are usually rare (Elkinton and Liebhold 1990). Outbreaks collapse due to a combination of food limitation, pathogens, and specialized parasites; all of which are largely unimportant in regulating low-density moth populations (Elkinton and Liebhold 1990). Mice, despite being dietary generalists (Wolff et al. 1985), are the principal predator on moth pupae and are capable of suppressing growth of low-density populations of gypsy moths (Campbell et al. 1977, Smith 1985, Elkinton et al. 1989, 1996, Ostfeld et al. 1996, Jones et al. 1998). Despite being an important predator of gypsy moth pupae, mice are numerically decoupled from moth abundance because acorn production, not moth pupal density, controls mouse abundance (Elkinton et al. 1996, Ostfeld et al. 1996) and because pupae are only available briefly during summer when food is not limiting (Wolff 1986, Krohne et al. 1991). Because mice cause high predation rates on pupae (Elkinton et al. 1996, Ostfeld et al. 1996, Jones et al. 1998), especially at low pupal densities (Elkinton et al. 1989, Schauber 2000, Schauber et al. 2004), an empirically parameterized model (Schauber 2000) indicated that mice should cause local moth extinction. Yet, as we will show, moths have persisted at our research site over a




23-year monitoring period at scales $>1$ ha, despite frequently going extinct at spatial scales $<1$ ha.

Foraging by white-footed mice is known to be spatially heterogeneous (Mittelbach and Gross 1984, Manson and Stiles 1998), which could lead to reduced predator efficacy in some locales (Gause 1935, Hassell et al. 1991). Gypsy moths also have relatively limited larval dispersal (Mason and McManus 1981, Weseloh 1997) and high fecundity (Elkinton and Liebhold 1990), two conditions that can produce high localized moth abundance and, subsequently, localized predator satiation (Turchin and Karieva 1989, Harrison 1997). We might also expect that the combination of spatially heterogeneous mouse foraging and limited moth larval dispersal could jointly contribute to population persistence. Limited dispersal could increase the likelihood that a sufficient number of larvae, hence pupae, would occur in locales where mouse foraging intensity is low, resulting in local predator satiation. In contrast, if larvae disperse widely throughout the landscape, then local pupal densities would always be low, and perhaps insufficient to locally satiate mouse predators even in locales where mouse foraging intensity is low. At the same time, a limited degree of larval dispersal, as opposed to no dispersal, would enable moths to move out of areas where high mouse predation rates would otherwise result in local extinction.

We postulated that limited larval dispersal and spatially heterogeneous mouse predation risk would interact synergistically to promote moth population persistence relative to either mechanism alone. Such an interaction could help account for observed spatial patterns of moth population persistence and might be of general relevance to the persistence of rare prey species facing high rates of incidental predation. Here we report findings from a spatially explicit, individual-based model parameterized with empirical data, which assesses this expectation for the gypsy moth-white-footed mouse system. Using the model we compared moth population persistence in scenarios that varied heterogeneity in mouse foraging and/or moth larval dispersal.

\section{Methods}

Gypsy moth density, scale of persistence, and refugia

Each female gypsy moth deposits a single egg mass, and thus, egg masses/ha can be used as an indicator of moth abundance. The density of gypsy moth egg masses was measured in forests dominated by oak (Quercus spp.) at the Institute of Ecosystem Studies (IES), Millbrook, New York, USA, from 1980 to 2003. Four different types of sampling plots were employed over the 23 years of sampling. We searched for egg masses in 20 permanent $78.5-\mathrm{m}^{2}$ plots (type A plots) every year from 1980 to 2003 in the autumn following oviposition. In these plots, all live trees, standing dead trees, fallen dead trees and attached limbs, woody debris, and rocks were searched for egg masses. All egg masses found
$<2 \mathrm{~m}$ above the ground were palpated to determine if they were oviposited recently or in prior years. Only recently oviposted egg masses were used in our analysis. When none of the type A plots had egg masses, then either another set of 20 permanent $491-\mathrm{m}^{2}$ plots (type B) were sampled $(1999,2001,2003)$ or incrementally larger areas were searched until a minimum of two recently oviposited egg masses were found (18.5 ha in 1986 and 10.8 ha in 1992). Sampling protocols for the type B plots and the incremental area searches were the same as for the type A plots. Finally, from 1995 to 1998 , an additional 72 permanent $225-\mathrm{m}^{2}$ plots (type C) were sampled. Twelve of these plots, randomly chosen, were sampled with the same protocol as the type A plots. On the remaining 60 type $\mathrm{C}$ plots, only live trees $>7 \mathrm{~cm}$ dbh were searched.

The spatial scale at which moths persist was estimated by determining the likelihood of encountering at least one egg mass as the spatial scale of sampling increased. Functionally, the spatial scale of sampling was increased by aggregating sample plots. For each of the four sampling regimes described in the previous paragraph (type A plots alone, type A plus type B plots, type A plots plus incremental area searches, and type C plots), the cumulative area sampled and whether at least one egg mass was encountered was determined for all the possible combinations of sampling plots (all the combinations of single plots, all the combinations of two plots, etc.) for each year the sampling regime was employed (19 years for type A plots alone, three years for type A plus type B plots, two years for type A plots plus incremental area searches, and four years for type $\mathrm{C}$ plots). The results were pooled across years. The proportion of samples with a particular cumulative area that had at least one egg mass present provided an index of the likelihood of moths persisting at that particular spatial scale.

If moths persisted due to permanent refugia, then egg masses found during low-density years (approximately equal to $<10 \mathrm{masses} / \mathrm{ha}$ ) would be expected to recur in the same locations. We analyzed the spatial distribution of egg masses visually by plotting the presence/absence of egg masses for each type A plot over the 23 years of monitoring. We also used the maximum number of years that egg masses were present on any one plot to assess the degree to which egg masses were concentrated on a few plots. If a few sites acted as permanent refugia, this number should be relatively large. We used a randomization approach to assess whether the observed distribution of egg masses was consistent with the null hypothesis that locations of egg masses are random among years. Within each year, the number of plots with egg masses present was the same in the randomization as the observed number, but the plots with egg masses were chosen randomly. This randomization was repeated one thousand times, and the observed maximum number of years that egg masses were present on any plot was compared to the sam- 
pling distribution produced by the 1000 randomizations.

\section{Simulation modeling: overview}

A spatially explicit, individual-based, empirically parameterized model tracked the location and life stage of individual moths over a 10-ha landscape. A 10-ha landscape was chosen since the lowest observed egg mass density was on the order of 1 egg mass/10 ha. In each annual generation, larvae dispersed from their natal egg masses. Larvae faced a constant $30 \%$ chance of mortality during dispersal (C. G. Jones, unpublished data), and surviving larvae pupated at their post-dispersal location. During the two week long pupal stage (Hough and Pimentel 1978), pupae faced potential predation by invertebrates (at a constant probability of $10 \%$ per day; C. G. Jones, unpublished data) and mice. Predation due to mice was influenced by both local mouse density and local moth pupal density. Surviving female pupae (assuming a 1:1 sex ratio) eclosed into adult moths that laid new egg masses. Based on the literature reports of egg mass size (Moore and Jones 1987, Williams et al. 1990) and hatch rates (Campbell and Sloan 1976, Moore and Jones 1992), egg masses were assumed to produce 250 larvae to start the next generation.

Since we were interested in moth persistence during periods of low moth density, model runs terminated with either moth extinction or outbreak initiation. A moth outbreak was treated as inevitable when densities surpassed 200 egg masses/ha. Simulated moth populations never went extinct above that density, even with mouse densities as high as 75 mice/ha, higher than any observed at our field site. The probability of a moth population persisting until an outbreak was initiated was calculated from 50 replicate model runs for each parameter set. In the main analyses, moth fecundity and larval mortality were held constant for each model run, but these parameters were varied during a sensitivity analysis.

\section{Simulation modeling: larval dispersal}

Adult female moths are flightless, so all dispersal occurs during the larval stage. Early-instar larvae disperse passively by ballooning on threads of secreted silk (Mason and McManus 1981). Although some ballooning larvae can be transported tens of kilometers (Mason and McManus 1981), field studies (Weseloh 1997, Erelli and Elkinton 2000, Hunter and Elkinton 2000) and modeling (Fosberg and Peterson 1986, Weseloh 1998) indicate that very few larvae attain such long distances, particularly within the forest canopy. Late instars may ambulate between trees at a rate of $\sim 5 \mathrm{~m} / \mathrm{d}$ (Weseloh 1985, Liebhold et al. 1986). How these two different types of movement collectively determine lifetime dispersal is unknown.

The impact of different dispersal patterns and degrees of dispersal limitation were evaluated by mod- eling larval dispersal either as complete mixing (random final location) or limited by a dispersal kernel (probability distribution of dispersal distances attained by the population of dispersing larvae). Kernel shape was either uniform (all distances equally likely out to a maximum distance) or negative exponential (short distances more likely with probability of dispersing a particular distance decaying exponentially with distance). While the true shape of the gypsy moth dispersal kernel is unknown, we expect that the shape should fall somewhere between these two extremes. Along with kernel shape, the maximum dispersal distance was varied to encompass the actual, but unknown, maximum lifetime dispersal distance. Some evidence suggests that most first instars disperse $<100 \mathrm{~m}$ in the forest canopy (Weseloh 1997, Erelli and Elkinton 2000, Hunter and Elkinton 2000), so we varied maximum lifetime larval dispersal from $25 \mathrm{~m}$ to $200 \mathrm{~m}$. With limited dispersal, each surviving larva dispersed from its natal egg mass in a random direction (drawn from a circular uniform distribution) and for a distance $(d)$ drawn from the dispersal kernel. For the uniform kernel $d=x k$, where $x$ is the maximum dispersal distance and $k[0,1)$ is a uniform random number $(\bar{d}=0.5 x)$. For the negative exponential kernel $d=x e^{-6 k}$, where the coefficient -6 ensures that the function has a value $<0.001$ when $k=1(\bar{d} \approx 0.166 x)$. Landscape boundaries were absorbing, so any larvae dispersing off the landscape were removed from the simulation.

\section{Simulation modeling: pupal predation}

Following dispersal, surviving larvae entered the pupal stage. Pupae were exposed to potential invertebrate and mouse predation for 14 days (the average time to adult eclosion; Hough and Pimentel 1978). Field experiments indicate that the risk of predation by whitefooted mice tends to be high at very low pupal density similar to a Type II functional response (Elkinton et al. 1989, Schauber 2000), although predation risk may increase further at moderate pupal densities (Schauber et al. 2004). We modeled the instantaneous per capita rate of pupal mortality caused by mouse predation using Holling's disk equation (Holling 1959). For each pupa, the daily risk of being eaten by a mouse was approximated as $P_{\mathrm{m}}=1-e^{-a m /\left(1+a \mathrm{th}_{\mathrm{h}}\right)}$ where $a$ is mouse attack rate, $m$ is local mouse density, $t_{\mathrm{h}}$ is mouse handling time, and $g$ is local (within $196 \mathrm{~m}^{2}$ ) pupal density on that day. Overall, daily predation risk was $P_{\mathrm{m}}+(1$ $\left.-P_{\mathrm{m}}\right) P_{\mathrm{i}}$, where $P_{\mathrm{i}}$ is daily risk of invertebrate predation. Based on field experiments that varied pupal densities, measured pupal predation (both mouse and invertebrate), and then estimated functional response parameters statistically (Schauber 2000), we used the following parameter values in the model: $a=0.025, t_{\mathrm{h}}=$ 0.12 , and $P_{\mathrm{i}}=0.1$.

Spatial heterogeneity in the risk of predation by mice was modeled by creating mouse density landscapes that varied in the range (difference between maximum and

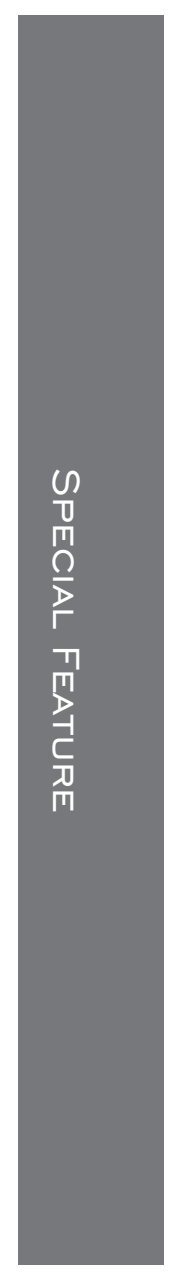




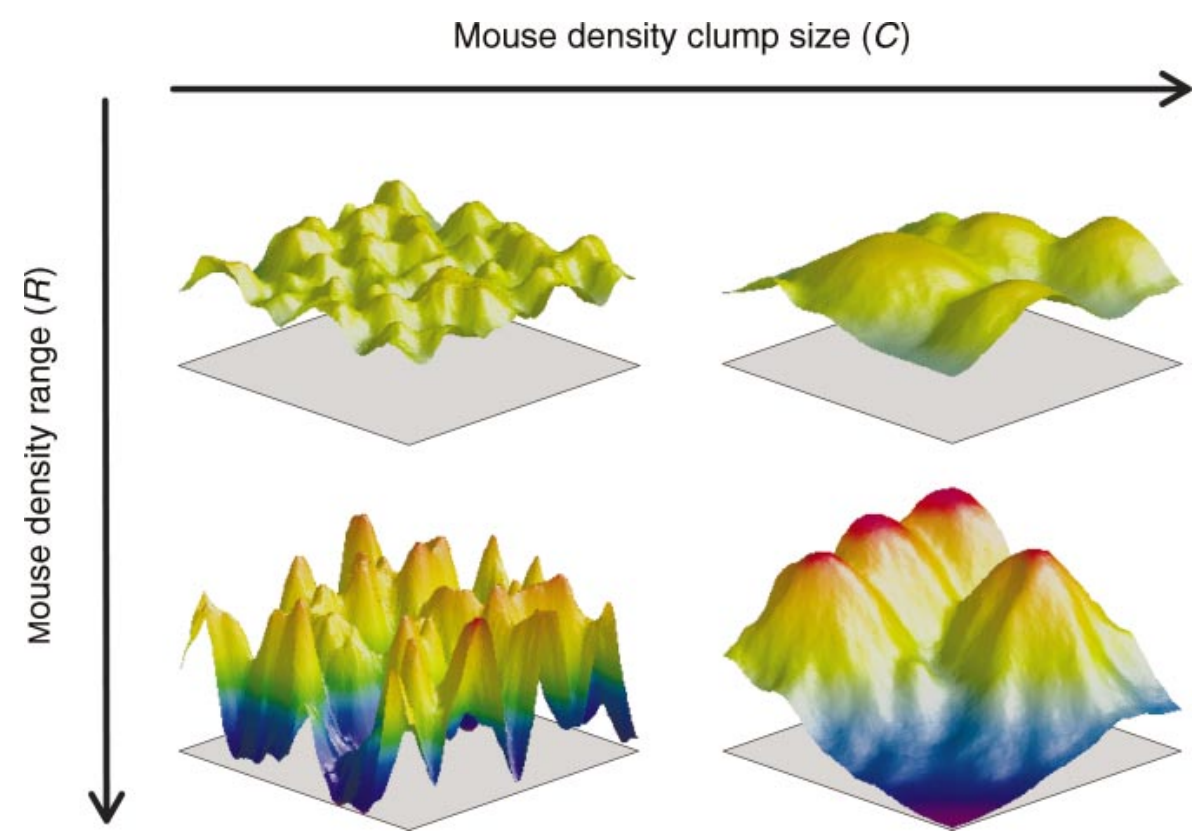

FIG. 1. Illustrative mouse densities over 10-ha landscapes for a spatially averaged density of 25 mice/ha. Surface height and color indicate local density (blue $=10 w$; red $=$ high). Rows are different mouse density ranges (landscape-wide average mouse density $\pm R=25 \%$ and $75 \%$; top and bottom, respectively), and columns are different mouse density clump sizes $(C=0.99$ and 0.9999 ; left and right, respectively). See Methods; Simulation modeling: pupal predation for an explanation of the algorithm that produced the mouse density surfaces. Mouse density surface height and local pupal density set predation risk for a pupa, but higher surface values represent greater predation risk at a given pupal density.

minimum local mouse density) and clump size (degree to which areas of high mouse density are found together) of mouse density (Fig. 1), using values that we expected to bracket the actual, but unknown, heterogeneity in mouse density. While many live-trapping studies show spatially heterogeneous trap success (Jorgensen 2004), trapping may not accurately represent mouse space use, because traps can truncate mouse movement and influence mouse behavior (trap attraction or repulsion). Patterns of foraging on seeds seem to indicate that mouse foraging is spatially auto-correlated at relatively short distances of 4-15 $\mathrm{m}$ (Manson 2000). The average surface height was set by $\bar{m}$ (average mouse density over the entire landscape), while surface topography was determined by parameters controlling the range $(R ; 0-100 \%)$ and clump size $(C ; 0-$ 1 ) of mouse density. The range varied from $R=0 \%$, indicating uniform mouse density over the entire landscape, to $R=100 \%$, indicating that mouse density ranged between 0 and $2 \bar{m}$. Clump sizes ranged from an area much smaller than a mouse home range to an area much larger than a mouse home range. Local mouse density was modeled as a surface on a $160 \times$ 160 grid of $2 \times 2 \mathrm{~m}$ cells (which equals a 10.24-ha landscape). This fine grid structure allowed us greater flexibility in modeling the spatial pattern of mouse predation both in terms of incorporating variations in predation risk at scale less than a mouse home range and incorporating convoluted edges for patches of high and low predation risk. Surfaces were constructed using the following approach. A set of $25600\left(160^{2}\right)$ local mouse density values $(m)$ was randomly drawn from a uniform distribution $[\bar{m}-\bar{m} \times R, \bar{m}+\bar{m} \times R)$ and sorted by mouse density. A random cell was seeded with the maximum value of $m$. The remaining values of $m$ were assigned to cells in descending order. For each value of $m$, a random empty cell was chosen and a uniform random number $(k,[0,1))$ was generated until either a touching cell had a density $\geq m$ or $k \geq C$, at which point the cell density was set to $m$ and the next value was drawn. This process was repeated until the landscape was filled. The resulting surface represented variation in predation risk as variation in local mouse density, but it could generally be thought of as representing spatial heterogeneity in predation risk due to any factor, such as local variation in predator search efficiency or local availability of alternative foods. We took this approach because it is unclear what processes might be causing spatial heterogeneity in predation by mice. The spatial pattern of mouse density was fixed for any given run, and, except for a mouse density range of $100 \%$ used for some runs, a finite predation risk occurred at all points in the landscape at all times. In other words, there were no absolute refugia in the landscape.

\section{Simulation modeling: interannual fluctuations in mouse density}

To add realism in predation risk, models were also run with fluctuating mouse densities. Interannual fluc- 



FIG. 2. (a) Gypsy moth egg mass density (no. egg masses per hectare) at the Institute of Ecosystem Studies (IES), Millbrook, New York, USA, 1980-2003. Symbols indicate the sampling scheme employed: type A plots only (•); type A and type B plots ( $\mathbf{\Lambda})$; type A and type C plots $(\square)$; and type A plots with cumulative area searched until at least two egg masses were found ( $\nabla ; 18.5$ ha in 1986 and 10.8 ha in 1992). See Methods; Gypsy moth density, scale of persistence, and refugia for plot types and sampling protocols. (b) Proportion of combinations of sampled plots with at least one egg mass present as a function of cumulative area sampled for each of the sampling schemes in panel (a). The resulting curves estimate the probability of gypsy moth intergenerational persistence at a given spatial scale for a given sampling scheme. Gray bars indicate the number of unique plot combinations that produce a particular cumulative sampled area.

tuations in mouse density caused by acorn masting (Elkinton et al. 1996, Ostfeld et al. 1996) were modeled by simulating acorn production using a stochastic second-order autoregressive model fitted to 19 years of acorn production in southwest Virginia. These data were used because the IES acorn time series is too short (11 years) for autoregressive modeling, and because both sites showed strong numerical response of mice to acorns and similar long-term average summer mouse densities (20-25 mice/ha). Based on acorn production and summer mouse densities at Mountain Lake Biological Station from 1980 to 1993 (Wolff 1996), spatially averaged mouse density in each year $\left(\bar{m}_{t}\right)$ was modeled as a positive, linear, heteroscedastic function of acorn production in the prior year (Schauber 2000). We then constructed a separate mouse density surface for each year based on $\bar{m}_{t}$.

\section{Model sensitivity analyses}

We systematically varied a number of key model parameters (moth fecundity, mouse attack rate, mouse handling time, landscape size, and boundary behavior) to assess the robustness of our findings. Values used for moth fecundity $(125,250$, or 375 hatched larvae/ egg mass), mouse attack rate $(0.013,0.025$, or 0.038 pupae $\cdot$ mouse $\left.\mathrm{e}^{-1} \cdot \mathrm{d}^{-1}\right)$, and mouse handling time $(0.06$, 0.12 , or $0.18 \mathrm{~d}$ ) were the estimates used in the standard models described above and 50\% increases or decreases in those estimates. For landscape size $(1,5$, or 10 ha), we considered smaller landscapes than those used in the described models, and we compared results between models with absorbing boundaries (the standard case) and wrapped boundaries.

\section{REsults}

\section{Gypsy moth density, scale of persistence, and refugia}

Gypsy moth egg mass density fluctuated by over five orders of magnitude over 23 years at IES (Fig. 2a), declining below $1 \mathrm{egg}$ mass/ha in four of those years. The lowest recorded density was $\sim 0.1 \mathrm{egg}$ masses/ha forest. For the type A plots, from which the longest time series of observations exist, plots were locally extinct $\sim 75 \%$ of the time, with a median length of 




FIG. 3. The presence/absence of egg masses on the type A sampling plots $(n=20)$ from 1981 to 2003 . Gray squares indicate presence of at least one egg mass in a given year, and each row corresponds to a single plot across years. The top panel shows the egg mass density time series to indicate times of low density. If spatially permanent refugia were important for moth persistence, then egg masses would be found on the same few plots during low-density years, producing a few plots with many observations of egg masses over the sampling period. The observed egg mass distribution is no more aggregated in a few plots during low-density years than we would expect by chance (see Results).

extinction of three years. Resampling of the density data showed that local extinction became increasingly likely below the 1-ha cumulative area sampled, but the probability of persistence approached unity at scales $>1$ ha (Fig. 2b).

The spatial distribution of egg masses present during low-density years did not suggest the presence of permanent refugia. Instead, egg masses were found on different plots during different low-density years (Fig. 3 ). The maximum number of years that egg masses were present on any plot was 9 of the 23 years, a value met or exceeded in $\sim 40 \%$ of the randomizations.

\section{Simulation modeling}

The combination of limited larval dispersal with heterogeneous predation risk always produced a greater probability of moth population persistence than either factor alone. For example, with $40 \mathrm{mice} / \mathrm{ha}$, both the case with limited larval dispersal and spatially homogeneous predation risk, and the case with spatially heterogeneous predation risk and complete larval mixing had a moth persistence probability of $0 \%$, but the combination of limited dispersal and spatially heterogeneous predation risk had a persistence probability of $\sim 75 \%$ (Fig. 4), indicating a nonadditive or synergistic effect of the two. Furthermore, neither limited larval dispersal nor heterogeneous predation risk alone was sufficient to explain moth persistence. When dispersal was limited but predation risk was spatially homogeneous, moth persistence probability was $100 \%$ only at $\leq 15$ mice/ha (44\% below median mouse densities observed at IES). Similarly, for heterogeneous predation risk with complete larval mixing, moth persistence was guaranteed only at $\leq 10 \mathrm{mice} / \mathrm{ha}(62 \%$ below median mouse density). However, limited dispersal combined with spatially heterogeneous predation risk permitted guaranteed moth population persistence at $25 \mathrm{mice} / \mathrm{ha}$, up to two-fold greater mouse densities than either limited dispersal or heterogeneous predation alone, and well within the range of observed mouse densities (Fig. 4). Sensitivity analyses indicate that this synergistic enhancement of moth persistence was very robust to fluctuating vs. constant mouse densities, $50 \%$ variation in mouse predation risk parameters (attack rate and handling time), 50\% variation in moth fecundity or larval mortality, a 10-fold variation in landscape area (1-10 ha), and wrapped vs. absorbing landscape edges.

Persistence probability was inversely related to dispersal distance (Fig. 5a-c). Greater larval dispersal dilutes larvae as they spread out from the natal egg mass,

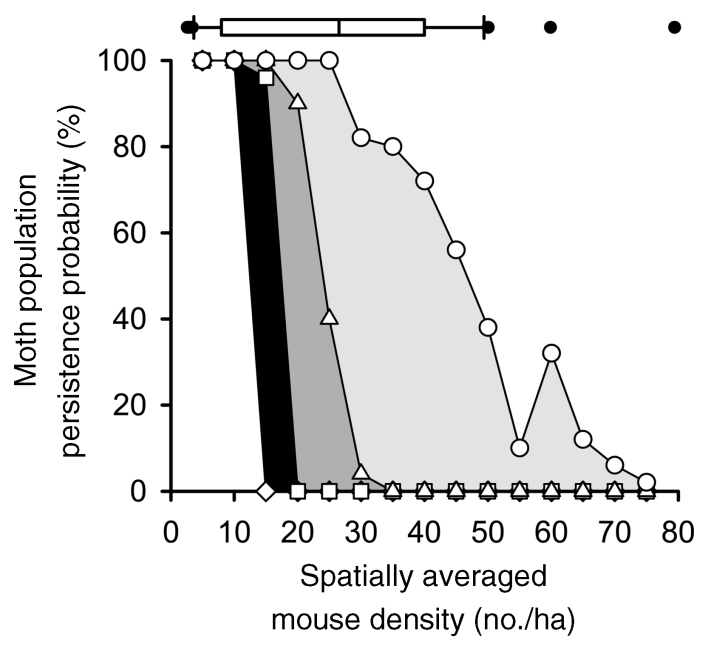

FIG. 4. Probability of moth population persistence vs. mouse density for spatially homogeneous predation risk with complete mixing $(\diamond)$, spatially heterogeneous predation risk ( $R=75 \%, C=0.999$ ) with complete mixing $(\square)$, spatially homogeneous predation risk with limited dispersal (negative exponential dispersal kernel with 200 m maximum dispersal; $\triangle)$, and spatially heterogeneous predation risk with limited dispersal $(R, C$, and dispersal kernel parameters combined from above; $\bigcirc)$. Mouse densities were kept constant within each model run. Shaded areas indicate incremental increase in moth persistence due to spatially heterogeneous predation (black), limited dispersal (dark gray), and the synergy of the two (light gray). The horizontal box plot (5th percentile, 25 th percentile, median, 75 th percentile, and 95 th percentile) and associated outliers (๑) show mid-July mouse densities at IES, based on six 2.25-ha trapping grids from 1995 to 2003. 

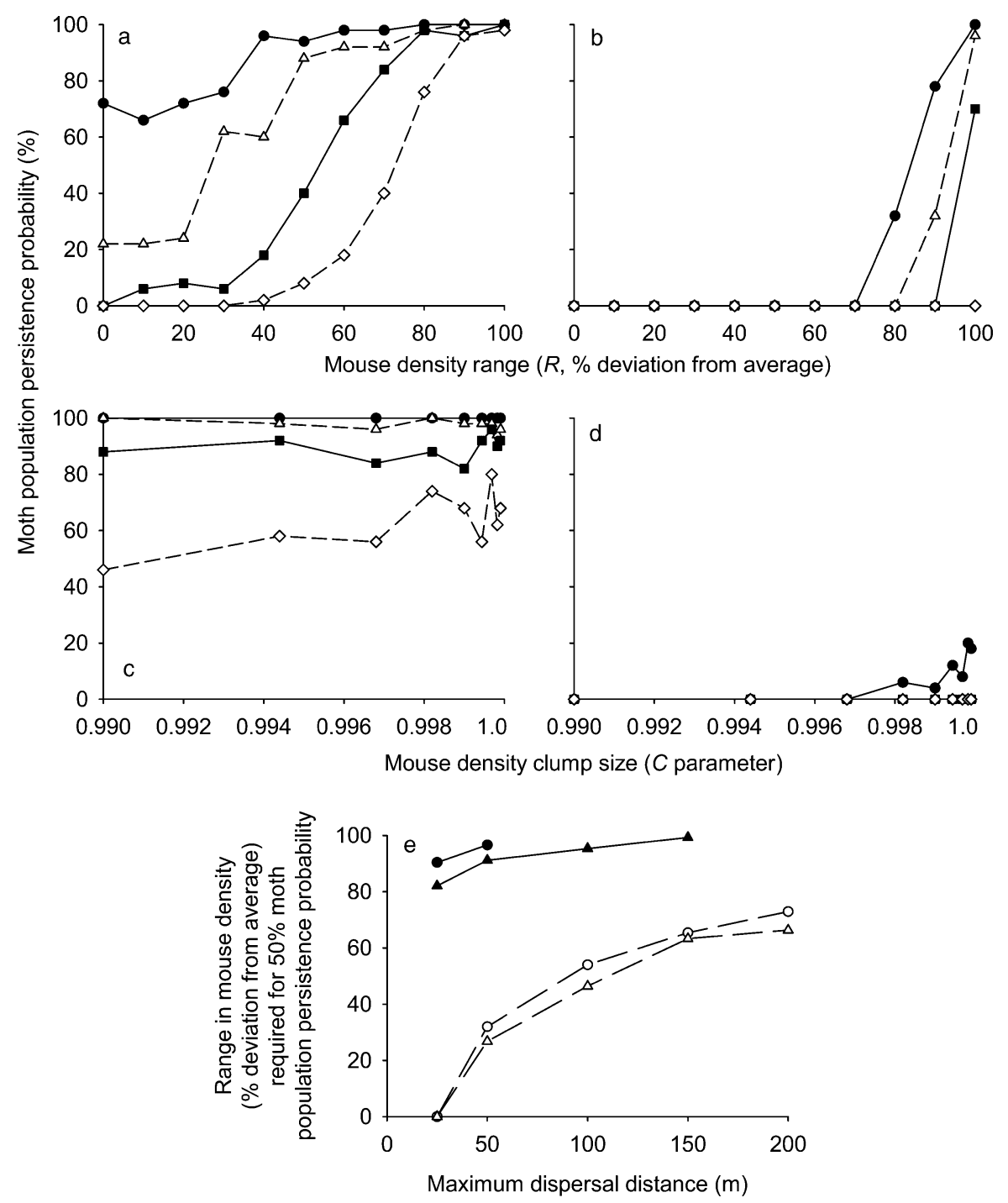

FIG. 5. Effect of limited dispersal and spatially heterogeneous predation risk on moth persistence. Persistence probability is plotted as a function of mouse density range (with constant clump size, $C=0.999$ ) for (a) negative exponential and (b) uniform dispersal kernels. Persistence probability is plotted as a function of mouse density clump size (with constant range, $R=90 \%$ ) for (c) negative exponential and (d) uniform dispersal kernels. In all four cases, maximum dispersal distances are $5 \mathrm{~m}(\bullet), 25 \mathrm{~m}(\triangle), 50 \mathrm{~m}(\boldsymbol{\bullet})$, and $100 \mathrm{~m}(\diamond)$. (e) Mouse density range required for a $50 \%$ probability of moth population persistence with uniform (solid line) or negative exponential (dashed line) dispersal kernels with either small clumps $(\bullet$ or O, $C=0.99$ ) or large clumps ( $\Delta$ or $\Delta, C=0.9999)$. In all cases, spatially averaged mouse density is $40 \mathrm{mice} / \mathrm{ha}$.

thereby decreasing larval density. In contrast, limited larval dispersal concentrates larvae in areas of low predation risk (where their parents survived to lay eggs) and elevates local larval densities. Elevated local larval densities translate into elevated pupal densities, potentially satiating local mice. For a given landscape-wide average mouse density, a high range of variation in local mouse density enhanced persistence by creating locales where predation was low enough for moths to survive, given sufficient local larval immigration (Fig. $5 \mathrm{a}, \mathrm{b})$. More limited dispersal reduced the range in mouse density required for a given persistence probability (Fig. 5e). Mouse density clump size had little influence on persistence (Fig. 5c). However, when moths dispersed longer distances, larger clumps of low mouse density increased the probability of dispersing moth larvae settling in an area of low predation risk (Fig. 5d).

\section{DisCUSSION}

Resampling analysis of the long-term egg mass survey data showed that gypsy moths are highly likely to go locally extinct at scales $<1$ ha, but persist at larger scales. How do gypsy moth populations manage to persist at these larger scales, when they are so vulnerable to mouse predation and local extinction? Several gen- 
eral processes might promote population persistence in the presence of abundant incidental predators. Permanent refugia can promote persistence (Hassell 1978), but gypsy moths tend to pupate in short-term refugia, such as bark crevices and man-made objects (Campbell et al. 1975, Campbell and Sloan 1976). To function as permanent refugia, these sites would have to be repeatedly discovered by moths and population contractions into such spatially fixed, permanent refugia during times of low moth density were not apparent from the egg mass surveys. Furthermore, even during lowdensity years, egg masses, and therefore the pupae that survived to produce those egg masses, tended to be out in the open on the base of trees and not under rocks, hidden in the litter, or in man-made objects $(99.4 \%$ of low-density egg masses were found $<2 \mathrm{~m}$ high on trees). Likewise, rescue by long-distance immigration can promote persistence (Brown and Kodric-Brown 1977, Hanski 1999), but this is unlikely in our system because females are flightless and long distance dispersal events are rare (Weseloh 1997). To consistently rescue a local population from extinction, either stable high-density populations near the focal site or highly asynchronous nearby populations would need to exist, but there is no evidence for either (Elkinton and Liebhold 1990). Similarly, density-dependent predation risk can promote persistence (Oaten and Murdoch 1975), but is unlikely to explain persistence in our system despite the per-mouse impact on pupal survival declining somewhat as gypsy moths become very scarce (Schauber et al. 2004), because predation risk still remains high enough (Elkinton et al. 1989, Schauber 2000) that moderate mouse densities can drive moths extinct.

Prior studies have suggested that reduced predator efficacy due to spatial heterogeneity in foraging (Gause 1935, Hassell et al. 1991) or predator satiation arising from limited prey dispersal that elevates local prey densities (Turchin and Karieva 1989, Harrison 1997) could promote persistence of prey. In this study, we assessed the effects of these factors acting both separately and together. In the empirically parameterized model, only the combination of limited dispersal and spatially heterogeneous predation resulted in moth population persistence at typical mouse densities. While the particular values for these two key parameters affected the degree of enhancement, population persistence was always enhanced whenever limited dispersal concentrated enough prey into areas of low predation. This general outcome was relatively insensitive to parameter values for moth fecundity, larval mortality, landscape size, and behavior of dispersing larvae at the landscape boundary. The robust synergistic interaction between limited moth dispersal and spatially heterogeneous risk of predation by mice, coupled with the lack of evidence substantiating other potential mechanisms for enhancing moth persistence, afford a possible explanation for how gypsy moth populations may persist in the face of intense incidental predation by mice.

Previous work on outbreaking insects suggests that threshold behavior, either in terms of predators or foliage availability, plays a key role in outbreak dynamics (Ludwig et al. 1978, 1979). Superficially, there is an analogous effect driving persistence in this model. If local moth abundance surpasses the threshold necessary to satiate local predation, then, at least locally, moth population growth will be positive. However, spatial heterogeneity of predation risk alone is not sufficient to stave off moth extinction. The critical aspect of our model, which is not involved in earlier threshold approaches to understanding insect outbreaks, is whether moth offspring spread out across the landscape or stay close to their natal site. These simulations show that, by staying close to the natal site, the likelihood of having positive population growth in the next generation is greatly increased.

This synergistic effect of limited dispersal and heterogeneous risk represents a novel mechanism of persistence that we term "spatial selection and satiation." Spatial selection is a passive process whereby the proportion of prey individuals in low-risk locales increases over time due to the mortality of individuals in highrisk locales and the tendency for offspring of survivors not to disperse out of low-risk locales. Through spatial selection, the synergy between spatially heterogeneous mortality risk (in this case due to mouse foraging) and limited dispersal enhances population persistence. Limited dispersal also increases the likelihood that sufficient numbers of prey occur in locales where predator foraging intensity is low, thereby satiating local predators. This satiation effect will be especially strong in cases where predator aggregative response is weak (e.g., generalists incidentally attacking rare prey). If prey were to disperse widely throughout the landscape, then local prey densities would always be low, and perhaps insufficient to locally satiate predators even in locales where predator foraging intensity is low. At the same time, a limited degree of dispersal, as opposed to no dispersal, would enable prey to move out of areas where high predation rates would otherwise result in local extinction. This model demonstrates the spatial selection and satiation effect when the pattern of predation risk is static over many generations of prey. The location of areas of low predation risk need not be constant but must occur nearby; that is, within the range of the limited prey dispersal, for the next generation.

Although this model was developed for white-footed mice preying on gypsy moths, in principle, spatial selection and satiation could enhance prey population persistence in many predator-prey systems. The necessary conditions for a predator-prey system to persist due to spatial selection and satiation would be: (1) mortality risk for the prey must be spatially heterogeneous, (2) prey fecundity must be high enough to 
locally satiate predators, (3) prey dispersal must be limited relative to the spatial pattern of mortality risk (that is, most offspring do not disperse far enough to leave areas of low risk), and (4) the spatial pattern of mortality risk must be decoupled from the spatial distribution of prey. Although predator satiation appears to be an important component in the mouse-moth system, the combination of spatial heterogeneity and limited dispersal may also enhance prey persistence without predator satiation by biasing the spatial distribution of prey toward areas of relatively low risk.

It has long been recognized that long-distance dispersal can enhance population persistence over large areas via metapopulation rescue effects (Hanski 1999), predator avoidance (Janzen 1970), and risk spreading (den Boer 1981). However, recent spatial models of specialist predator-prey systems have shown that limited movement rates of both predator and prey (i.e., diffusion limitation) can enhance stability by inducing negative spatial correlation between predator and prey (de Roos et al. 1991, Keeling et al. 2000). In the generalist predator-rare prey case, spatial selection and satiation due to the synergy of limited dispersal and heterogeneous predation risk may produce a similar negative spatial correlation between prey and predator. We suggest that this spatial selection and satiation effect is especially crucial for persistence of rare prey incidentally attacked by generalist predators because, unlike specialist predators, prey rarity does not depress local abundance of generalists. Many species are rare (May 1975) and many may experience high rates of incidental predation (Murdoch and Bence 1987, Savidge 1987, Wilson et al. 1998), so the gypsy mothmouse system may be representative of predation scenarios experienced by rare species across a range of ecosystems and taxa. In these cases, models that do not account for limited dispersal and heterogeneous predation risk will likely overestimate extinction rates. For example, using spatially averaged estimates of predation risk and assuming complete prey mixing, one might come to believe that a population is a sink (Pulliam and Danielson 1991), when it might act as a source or a sink depending on the degree of spatial heterogeneity in risk and how limited prey dispersal is. In managing species of conservation interest or irruptive pests that are often rare, like the gypsy moth, actions that alter spatial patterns of prey dispersal and predation risk may have greater impacts on prey persistence than manipulations of mean predator density.

ACKNOWLEDGMENTS

We thank J. Hart and L. Christenson for helping compile data. The Andrew W. Mellon Foundation, National Science Foundation, and the Institute of Ecosystem Studies provided financial support. This is a contribution to the program of the Institute of Ecosystem Studies.

\section{Literature Cited}

Brown, J. H., and A. Kodric-Brown. 1977. Turnover rates in insular biogeography: effect of immigration on extinction. Ecology 58:445-449.
Campbell, R. W., D. L. Hubbard, and R. J. Sloan. 1975. Location of gypsy moth (Lepidoptera, Lymantriidae) pupae and subsequent pupal survival in sparse, stable populations. Environmental Entomology 4:597-600.

Campbell, R. W., and R. J. Sloan. 1976. Influence of behavioral evolution on gypsy moth pupal survival in sparse populations. Environmental Entomology 5:1211-1217.

Campbell, R. W., R. J. Sloan, and C. E. Biazak. 1977. Sources of mortality among late instar gypsy moth larvae in sparse populations. Environmental Entomology 6:865-871.

den Boer, P. J. 1981. On the survival of populations in a heterogeneous and variable environment. Oecologia 50: 39-53.

de Roos, A. M., E. McCauley, and W. G. Wilson. 1991. Mobility versus density-limited predator-prey dynamics on different spatial scales. Proceedings of the Royal Society of London, Series B 246:117-122.

Elkinton, J. S., J. R. Gould, A. M. Liebhold, H. R. Smith, and W. E. Wallner. 1989. Are gypsy moth populations in North America regulated at low density? Pages 233-249 in W. E. Wallner and K. A. McManus, editors. Lymantriidae: a comparison of features of New and Old World tussock moths. USDA Forest Service, Northeastern Forest Experiment Station, Hamden, Connecticut, USA.

Elkinton, J. S., W. M. Healy, J. P. Buonaccorsi, G. H. Boetner, A. M. Hazzard, H. R. Smith, and A. M. Liebhold. 1996. Interactions among gypsy moths, white-footed mice, and acorns. Ecology 77:2332-2342.

Elkinton, J. S., and A. M. Liebhold. 1990. Population dynamics of gypsy moth in North America. Annual Review of Entomology 35:571-596.

Erelli, M. C., and J. S. Elkinton. 2000. Factors influencing dispersal in neonate gypsy moths (Lepidoptera: Lymantriidae). Environmental Entomology 29:509-515.

Fosberg, M. A., and M. Peterson. 1986. Modeling airborne transport of gypsy moth (Lepidoptera: Lymantriidae) larvae. Agricultural and Forest Meteorology 38:1-8.

Gause, G. F. 1935. The struggle for existence. Williams and Wilkins, Baltimore, Maryland, USA.

Hanski, I. 1999. Metapopulation ecology. Oxford University Press, Oxford, UK.

Harrison, S. 1997. Persistent, localized outbreaks in the western tussock moth Orgyia vetusta: the roles of resource quality, predation and poor dispersal. Ecological Entomology 22:158-166.

Hassell, M. P. 1978. Arthropod predator-prey systems. Volume 13. Princeton University Press, Princeton, New Jersey, USA.

Hassell, M. P., R. M. May, S. W. Pacala, and P. L. Chesson. 1991. The persistence of host-parasitoid associations in patchy environments. I. A general criterion. American Naturalist 138:568-583.

Holling, C. S. 1959. The components of predation as revealed by a study of small-mammal predation of the European pine sawfly. Canadian Entomologist 91:293-320.

Hough, J. A., and D. Pimentel. 1978. Influence of host foliage on development, survival, and fecundity of the gypsy moth. Environmental Entomology 7:97-102.

Hunter, A. F., and J. S. Elkinton. 2000. Effects of synchrony with host plant on populations of a spring-feeding lepidopteran. Ecology 81:1248-1261.

Janzen, D. H. 1970. Herbivores and the number of tree species in tropical forests. American Naturalist 104:501-528.

Jones, C. G., R. S. Ostfeld, M. P. Richard, E. M. Schauber, and J. O. Wolff. 1998. Chain reactions linking acorns to gypsy moth outbreaks and Lyme disease risk. Science 279: 1023-1026.

Jorgensen, E. E. 2004. Small mammal use of microhabitat reviewed. Journal of Mammalogy 85:531-539.

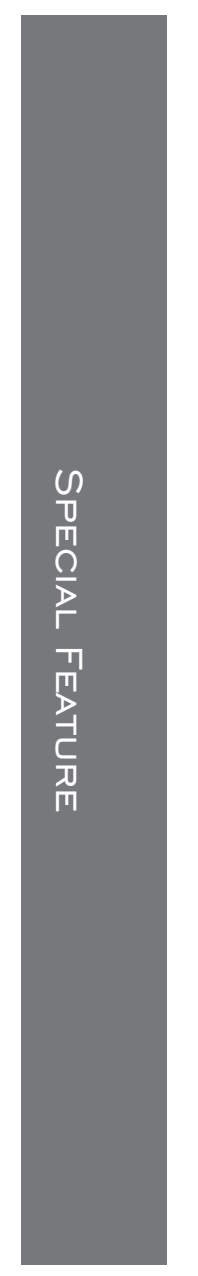


Keeling, M. J., H. B. Wilson, and S. W. Pacala. 2000. Reinterpreting space, time lags, and functional responses in ecological models. Science 290:1758-1761.

Krohne, D. T., T. J. Couillard, and J. C. Riddle. 1991. Population responses of Peromyscus leucopus and Blarina brevicauda to emergence of periodical cicadas. American Midland Naturalist 126:317-321.

Liebhold, A. M., J. S. Elkinton, and W. E. Wallner. 1986. Effect of burlap bands on between-tree movement of lateinstar gypsy moth, Lymantria dispar (Lepidoptera: Lymantriidae). Environmental Entomology 15:373-379.

Liebhold, A. M., J. A. Halverson, and G. A. Elmes. 1992. Gypsy moth invasion in North America: a quantitative analysis. Journal of Biogeography 19:513-520.

Ludwig, D., D. Aronson, and H. F. Weinberger. 1979. Spatial patterning of the spruce budworm. Journal of Mathematical Biology 8:217-258.

Ludwig, D., D. D. Jones, and C. S. Holling. 1978. Qualitative analysis of insect outbreak systems: the spruce budworm and forest. Journal of Animal Ecology 47:315-332.

Manson, R. H. 2000. Spatial autocorrelation and the interpretation of patterns of tree seed and seedling predation by rodents in old-fields. Oikos 91:162-174.

Manson, R. H., and E. W. Stiles. 1998. Links between microhabitat preferences and seed predation by small mammals in old fields. Oikos 82:37-50.

Mason, R. R., and M. L. McManus. 1981. Larval dispersal of the gypsy moth. Pages 161-202 in C. C. Doane and M. L. McManus, editors. The gypsy moth: research toward integrated pest management. Technical Bulletin 1574. USDA, Washington, D.C., USA.

May, R. M. 1975. Patterns of species abundance and diversity. Pages 81-120 in M. L. Cody and J. M. Diamond, editors. Ecology and evolution of communities. Harvard University Press, Cambridge, Massachusetts, USA.

Mittelbach, G. G., and K. L. Gross. 1984. Experimental studies of seed predation in old-fields. Oecologia 65:7-13.

Moore, K. E. B., and C. G. Jones. 1987. Field estimation of fecundity of gypsy moth (Lepidoptera: Lymantriidae). Environmental Entomology 16:165-167.

Moore, K. E. B., and C. G. Jones. 1992. Estimating field hatch of gypsy moth (Lepidoptera: Lymantriidae). Environmental Entomology 21:276-280.

Murdoch, W. W., and J. Bence. 1987. General predators and unstable prey populations. Pages 17-30 in W. C. Kerfoot and A. Sih, editors. Predation: direct and indirect impacts on aquatic communities. University Press of New England, Hanover, New Hampshire, USA.

Oaten, A., and W. W. Murdoch. 1975. Functional response and stability in predator-prey systems. American Naturalist 109:289-298.

Ostfeld, R. S., C. G. Jones, and J. O. Wolff. 1996. Of mice and mast: ecological connections in eastern deciduous forests. BioScience 46:323-330.
Pulliam, H. R., and B. J. Danielson. 1991. Sources, sinks, and habitat selection: a landscape perspective on population dynamics. American Naturalist 137:S50-S65.

Savidge, J. A. 1987. Extinction of an island forest avifauna by an introduced snake. Ecology 68:660-668.

Schauber, E. M. 2000. Models of mast seeding and its ecological effects on gypsy moth populations and Lyme-disease risk. Dissertation. University of Connecticut, Storrs, Connecticut, USA.

Schauber, E. M., R. S. Ostfeld, and C. G. Jones. 2004. Type 3 functional response of mice to gypsy moth pupae: Is it stabilizing? Oikos 107:592-602.

Schmidt, K. A., J. R. Goheen, and R. Naumann. 2001. Incidental nest predation in songbirds: behavioral indicators detect ecological scales and processes. Ecology 82:29372947.

Smith, H. R. 1985. Wildlife and the gypsy moth. Wildlife Society Bulletin 13:166-174.

Turchin, P., and P. Karieva. 1989. Aggregation in Aphis varians: an effective strategy for reducing predation risk. Ecology 70:1008-1016.

Weseloh, R. M. 1985. Dispersal, survival, and population abundance of gypsy moth, Lymantria dispar (Lepioptera: Lymantriidae), larvae determined by releases and markrecapture studies. Annals of the Entomological Society of America 78:728-735.

Weseloh, R. M. 1997. Evidence for limited dispersal of larval gypsy moth, Lymantria dispar L. (Lepidoptera: Lymantriidae). Canadian Entomologist 129:355-361.

Weseloh, R. M. 1998. Modeling the influence of forest characteristics and ant (Formicidae: Hymenoptera) predation on dispersal and survival of neonate gypsy moths (Lymantriidae: Lepidoptera). Environmental Entomology 27: 288-296.

Williams, D. W., R. W. Fuester, W. W. Metterhouse, R. J. Balaam, R. H. Bullock, R. J. Chianese, and R. C. Reardon. 1990. Density, size, and mortality of egg masses in New Jersey population of the gypsy moth (Lepidoptera: Lymantriidae). Environmental Entomology 19:943-948.

Wilson, P. R., B. J. Karl, R. J. Toft, J. R. Beggs, and R. H. Taylor. 1998. The role of introduced predators and competitors in the decline of kaka (Nestor meridionalis) populations in New Zealand. Biological Conservation 83:175185.

Wolff, J. O. 1986. The effects of food on midsummer demography of white-footed mice, Peromyscus leucopus. Canadian Journal of Zoology 64:855-858.

Wolff, J. O. 1996. Population fluctuations of mast-eating rodents are correlated with production of acorns. Journal of Mammalogy 77:850-856.

Wolff, J. O., R. D. Duesser, and K. S. Berry. 1985. Food habits of sympatric Peromyscus leucopus and Peromyscus maniculatus. Journal of Mammalogy 66:795-798. 